\title{
1-Cyclohexylpiperidine as a Thermolytic Draw Solute for Osmotically Driven Membrane Processes
}

\author{
Christopher J. Orme and Aaron D. Wilson* \\ Idaho National Laboratory, P.O. Box 1625 MS 3531, Idaho Falls, ID 83415-3531, USA \\ aaron.wilson@inl.gov, voice (208) 526-1103
}

The switchable polarity solvent (SPS) 1-cyclohexylpiperidine (CHP) was demonstrated as a viable draw solute for osmotically driven membrane processes. The SPS draw solution was formed from a heterogeneous mixture of water and water immiscible CHP was exposed to carbon dioxide to form concentrated aqueous ammonium bicarbonate solution with high osmotic pressure (>500 atm). The free amine and ammonium bicarbonate solution has been demonstrated to be compatible with a polyamide thin film composite membrane through a variety of transport experiments. The reverse solute flux, $J_{s}$, of CHP appears to occur by a different mechanism than the water flux $J_{w}$. This difference suggests that $J_{s}$ could be minimized in future membranes without impacting $J_{w}$. To demonstrate product water recovery, the solution was “degassed" removing carbon dioxide and converting the aqueous ammonium bicarbonate solute to a water immiscible CHP which can be decanted from water. Effective degassing ammonium bicarbonate solutions at low concentrations occurs at the lowest temperature of any SPS yet studied as a draw solute $\left(70{ }^{\circ} \mathrm{C}\right)$ and possibly at the lowest temperature of any thermolytic amine studied as a draw solute.

Keywords: Forward osmosis, desalination, switchable polarity solvents, draw solution, osmotically driven membrane process. 


\section{INTRODUCTION}

The potential of thermolytic draw solutes has driven much of the recent interest forward osmosis (FO) and osmotically driven membrane processes (ODMP) in general [1,2]. The number of thermolytic draw systems reported in the literature has been rapidly expanding [3-9]. Previously our group reported the use of switchable polarity solvents (SPS), specifically dimethylcyclohexylamine (DMCHA)[10], as a thermolytic draw solute, Reaction 1 [11]. This allowed the proposal of a switchable polarity solvent forward osmosis (SPS-FO) process illustrated in Figure 1. The driving force for this water treatment technology is supplied as heat in the degasser. Even if more energy is required for SPS-FO, as a thermally driven process SPS-FO may be a more cost effective than electrically driven processes such as osmotic filtrations (including reverse osmosis (RO) and ultrafiltration/nanofiltration (UF/NF) of dissolved solids). High grade heat energy is approximately a tenth the cost of electricity per unit energy so even with lower energy efficiency a thermal process can have a low cost. FO also offers potential reduced fouling issues and pretreatment requirements when compared to reverse osmosis (RO) [12-16]. Pretreatment costs are often $60 \%$ of the cost to treat oil and gas water with RO versus the core hydraulic RO energy requirements contributing only $\sim 20 \%$ of the total treatment cost. SPS-FO has the potential to be driven by low grade heat which can be obtained at an even great discount from industrial processes, solar heat, or geothermal source.

$$
\mathrm{NR}_{3(\mathrm{org})}+\mathrm{CO}_{2(\mathrm{~g})}+\mathrm{H}_{2} \mathrm{O} \rightleftharpoons \mathrm{HNR}_{3}^{+}{ }_{(\mathrm{aq})}+\mathrm{HCO}_{3}^{-}{ }_{(\mathrm{aq})}
$$




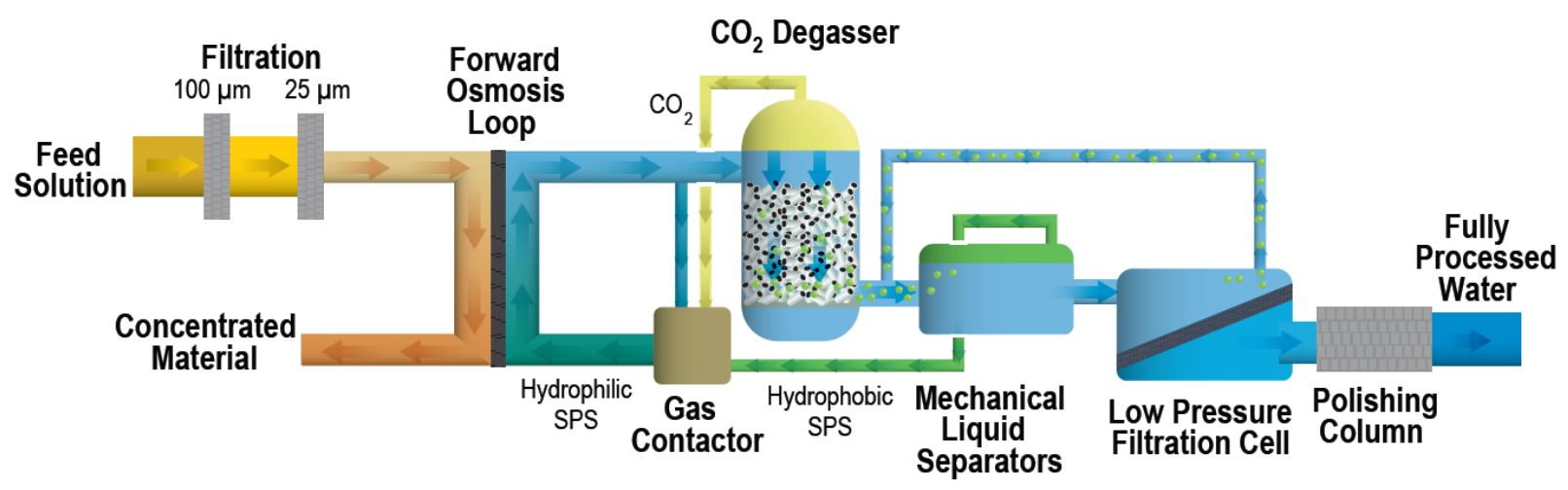

Figure 1. Proposed a switchable polarity solvent forward osmosis (SPS-FO) process.

DMCHA offered a draw system that could achieve extraordinarily high osmotic pressures [17] and in theory the draw solute could be removed from the product water through the application of low grade heat. A major drawback of DMCHA is its chemical aggressiveness towards a number of polymeric materials and membranes. DMCHA degrades cellulose triacetate membranes and even softens and leaches materials from most polyethylenes and polypropylenes. The polar-to-nonpolar switch or degassing step was also an issue for DMCHA. The degassing process is the key method by which the draw solute is separated from the product water. These degassing challenges are similar to the challenges empirically documented for the ammonia- $\mathrm{CO}_{2}$ system $[18,19]$.

Given the problems with DMCHA our group sought an SPS better optimized for use as a draw solute. The ideal SPS amine draw solute would feature: 1) effective polar-to-nonpolar phase transition (rapid, low temperature, and complete), 2) low SPS water solubility of the non-polar form, 3) low SPS membrane permeability, 4) compatibility with a wide range of materials, 5) high osmotic pressure in the polar form, and 6) good osmotically driven membrane process flux kinetics. Features 1-4 are all expected to improve by moving from DMCHA to an amine with a higher molecular mass and increased organic character. The benefits associated with increased molecular mass must be balanced against reduced osmotic pressure and reduced flux kinetics both of which generally drop with increased molecular mass. To find the balance point our group conducted a structure function study of tertiary amines to measure the 
equilibrium concentration of the polar SPS form provided an unlimited supply of amine and $\mathrm{CO}_{2}$ at a fixed pressure [20]. This study resulted in a quantitative structure activity relationship (QSAR) model for SPS’s key function. The QSAR model indicated including ring systems which are near or included the nitrogen such as cyclohexyl groups, pyrrolidines, and piperidines facilitates reaching high concentrations in the polar form [20]. Density functional theory (DFT) studies demonstrated that the ring system constrains the organic groups preventing steric disruption at the amine proton [21]. In response we investigated 1-cyclohexylpiperidine (CHP), featuring two ring systems around the nitrogen center. A number of CHP properties are predicted to provide improvements over DMCHA, such as boiling point $\left(158-159{ }^{\circ} \mathrm{C} \rightarrow 230-234{ }^{\circ} \mathrm{C}\right)$, flash point $\left(42.2^{\circ} \mathrm{C} \rightarrow 101.4^{\circ} \mathrm{C}\right)$ [22], vapor pressure $(2.2 \mathrm{mmHg} \rightarrow 0.1$ mmHg at $25^{\circ} \mathrm{C}$ ) [22]. Here we report initial membrane compatibility, FO flux performance, reverse solute flux, and initial degassing experiments.

\section{EXPERIMENTAL METHODS}

\subsection{General}

Deionized water was used for this experiment. 1-cyclohexylpiperidine 97\% (CHP) from AlfaAesar and $N, N$-dimethylcyclohexylamine 99\% (DMCHA) was obtained from Aldrich and used as received. All equipment was used in accordance with manufacturer specification unless stated otherwise. Freezing point depression osmometry was performed using an Advanced Instruments Inc. Model 3250 Osmometer.

\subsection{Production of 1-cyclohexylpiperidinium bicarbonate draw solute}

Deionized water (229.67 g) and CHP (221.21 g, $1.32 \mathrm{~mol})$ are placed in a bottle equipped with a gas diffuser and exposed to a steady stream of carbon dioxide $(30 \mathrm{ml} / \mathrm{min})$ supplied by a mass transfer 
system, consisting of a gas cylinder and a mass flow controller, for 4 days while being stirred with a magnetic stirring bar. After $\sim 48 \mathrm{hrs}$ the solution reached equilibrium with approximately $10 \mathrm{ml}$ of organic material unreacted, the purge was continued for an addition 48 hrs to ensure the equilibrium had been met. The product aqueous layer was a yellow clear homogenous solution with a mass of $491.44 \mathrm{~g}$ whose material properties have been previously published [23]. Similar stock solutions were then diluted to the desired concentration and concentration validated with freezing point depression osmometry.

\subsection{Forward Osmosis Water Flux and Reverse Solute Flux Experiments}

Fresh membranes were soaked in deionized water for at least 30 minutes prior to their introduction to the flow cell. The membrane was exposed to the flowing feed solution and a small volume of pure water to bring it to the equilibrium temperature. To begin an experiment, an already flowing and temperature controlled draw solution was redirected to the membrane surface opposite the feed solution. A feed solution ( $200 \mathrm{ml})$ of varying $\mathrm{NaCl}$ concentrations and a draw solution $(\sim 50 \mathrm{ml}, 7.6 \mathrm{~mol} / \mathrm{kg}$ $\left[\mathrm{H}(\mathrm{CHP}) \mathrm{HCO}_{3}\right]$ ) were passed across opposing sides of an FO polyamide thin film composite membrane (Porifera FOMEM-0513) in a Sterlitech PTFE FO cell with an active membrane area of $A_{m}=42.1 \mathrm{~cm}^{2}$ an flow path cross section of $1.05 \mathrm{~cm}^{2}$ for each half of the cell. The membrane's active layer was oriented towards the feed solution and the support layer oriented towards the draw solution (FO mode). All system components consisted of fluorinated polymers or stainless steel. The feed and draw solutions were maintained at a constant temperature of $25^{\circ} \mathrm{C}$ and flow rate of $300 \mathrm{ml} / \mathrm{min}$ with magnetically driven gear pumps producing linear velocities $6 \mathrm{~cm} / \mathrm{sec}$ at the membrane surface. The draw solution was bathed in ambient flow of carbon dioxide (30 ml/minute). The draw solution was situated on a scale and its mass measured with a computer every 20 seconds. The mass of the feed solution was given $\sim 30$ minutes to stabilize before readings were obtained 6 sec over various periods of time. These time period, $t_{1}$, and membrane area were then used to calculate the water flux, $J_{w}$, via Equation 2. For all $J_{w}$ reported the standard deviation was $\pm 0.5 \mathrm{Kg} / \mathrm{m}^{2} \mathrm{hr}$ or less. 


$$
J_{w}=\frac{M_{D 1}-M_{D 0}}{A_{m} t_{1}}
$$

The reverse solute flux, $J_{s}$, was calculated by collecting samples periodically during the experiment and comparing them to an initial sample. The initial concentration of $\mathrm{CHP}, C_{F 0}$, was measured via the GC volume discussed below and used with the initial feed solution volume, $V_{F 0}$, to calculate an initial quantity of CHP in solution. The same data, $C_{F 1}$ and $V_{F 1}$, was collected for a second sample at a given time $t_{1}$. The final quantity was adjusted for the initial quantity and divided by the membrane area $A_{m}$ and elapsed time $t_{1}$. The standard deviation for $J_{s}$ measurements was $\pm 2 \%$ or less.

$$
J_{s}=\frac{C_{F 1} V_{F 1}-C_{F 0} V_{F 0}}{A_{m} t_{1}}
$$

CHP concentration in the feed solution was quantified using Gas Chromatography (GC). GC analyses were carried-out using a HP (Agilent) 5890 GC equipped with a flame Ionization detector (FID). The GC column used in this work is a Restek ${ }^{\circledR}$-Rtx-5, 30 m length, 0.25 mm ID, and $0.25 \mathrm{~mm}$ film thickness. Injections were made using an auto sampler with a $1 \mu \mathrm{l}$ injection volume and a split ratio 10:1, the injection temperature was set to $250{ }^{\circ} \mathrm{C}$. The oven program used: initial temperature set to $100{ }^{\circ} \mathrm{C}$ with a hold for $1 \mathrm{~min}$ than ramped to $200{ }^{\circ} \mathrm{C}$ at $15^{\circ} \mathrm{C} / \mathrm{min}$ with a final ramp to 300 at $50 \mathrm{C} / \mathrm{min}$. UHP Helium was used as the carrier gas at a linear velocity of $30 \mathrm{~cm} / \mathrm{sec}$. The FID detector was held at constant $\left.275^{\circ} \mathrm{C}.\right)$

\subsection{Draw solution degassing studies}

Concentrated draw solutions $\left[\mathrm{H}(\mathrm{DMCHA}) \mathrm{HCO}_{3}\right]$ and $\left[\mathrm{H}(\mathrm{CHP}) \mathrm{HCO}_{3}\right]$ were diluted to 1.3 $\mathrm{mol} / \mathrm{Kg}$ by amine or $2.5 \mathrm{Osm} / \mathrm{Kg}$ with a mass of solution between $140-250 \mathrm{~g}$. A gear pump was used to recirculate the ammonium bicarbonate solution through a heat exchanger column (vertical inlets) featuring a high surface area honeycomb interior. The solution was pumped at a rate sufficient to 
homogenize the heterogeneous liquid mixture. The degasser was held at a fixed temperature by circulating heated liquids through the heat exchangers second path (lateral inlets). Samples of $\sim 4 \mathrm{ml}$ were periodically obtained and allowed to phase separate. Freezing point depression osmometry data was measured in at least duplicate for the aqueous phase of these samples.

\section{RESULTS AND DISCUSSION}

\subsection{Osmotic Pressure}

Our previous study resulted in a QSAR model capable of predicting the equilibrium concentration of a tertiary ammonium bicarbonate solution when an unlimited supply of amine and $\mathrm{CO}_{2}$ are exposed to a defined quantity of water [20]. This concentration correlates with the SPS's maximum osmotic pressure $[17,23]$. The QSAR model indicated the value of rings systems in the function of SPS but appears to have understated their importance. In the case of CHP the QSAR model predicted an equilibrium concentration of about 2.3 M by amine (4.2 mol/Kg by amine) or about $190 \mathrm{~atm}$ based on common SPS properties. This was a significant underestimate with an empirical maximum concentration of $3.4 \mathrm{M}$ by amine (11.2 $\mathrm{mol} / \mathrm{Kg}$ by amine) and a projected osmotic pressure of $>500 \mathrm{~atm}$.

CHP included a number of other unexpected characteristics. In the polar form CHP has an amine:carbonic acid ratio of 1.00:1, the lowest ratio observed thus far an SPS. CHP is also the first SPS tertiary-amine to have a carbon count higher than 10 (without the inclusion of glycol functionality [24]) and display osmotic activity. Diluting a 1-cyclohexylpiperidinium bicarbonate solution produces a very linear relationship between concentration and freezing point depression, Figure 2. Projecting from this dilute data suggests the maximum osmotic pressure is in excess of $500 \mathrm{~atm}$. While this osmotic pressure is less than full concentration dimethylcyclohexylammonium bicarbonate solution ( 835 atm),[20] CHP is likely above the threshold where specific osmotic pressure is a significant factor in FO flux. There is evidence that as osmotic pressures increase there are diminishing returns in terms of osmotic flux [1,25- 
30]. Any osmotic pressure over the $370 \mathrm{~atm}$, the osmotic pressure of an ideal saturated $\mathrm{NaCl}$ solution, is likely less important than solute and solution properties like diffusion and viscosity.

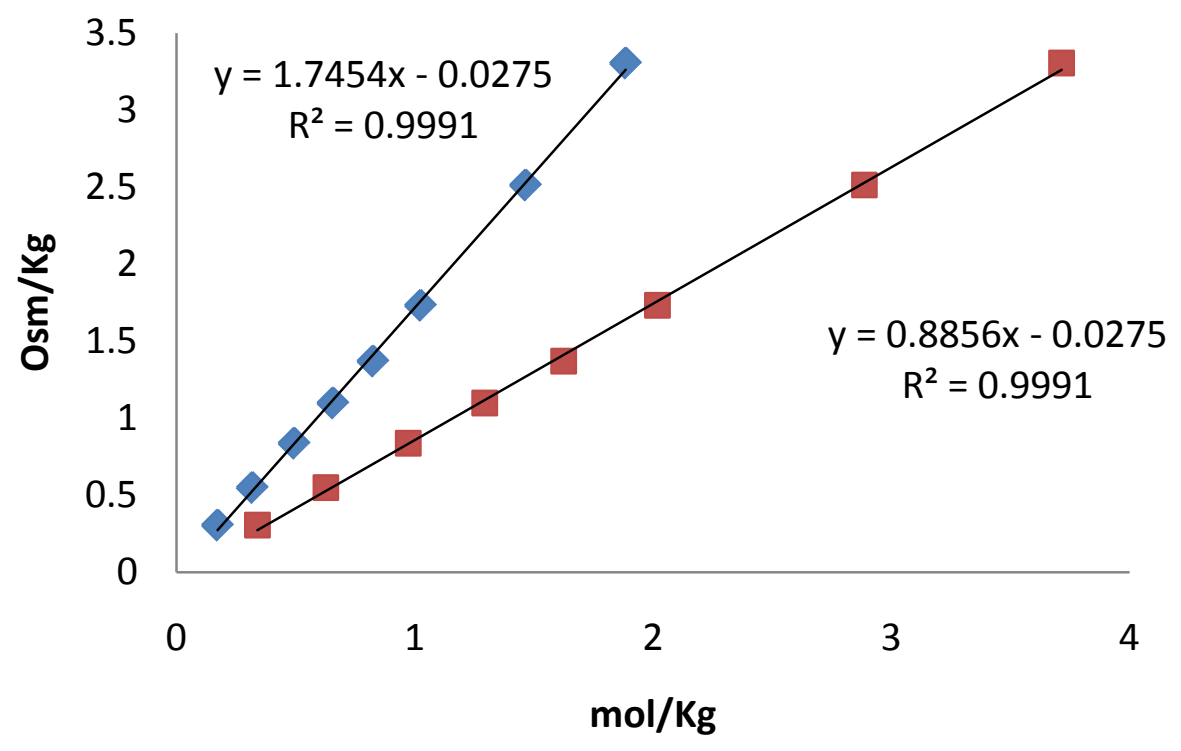

Figure 2. The van't Hoff plot for 1-cyclohexylpiperidinium bicarbonate. The diamonds are molality of amine and ammonium ions. The squares are the total species molality including amines, ammonium ions, and carbonate species.

\subsection{Flux Experiments}

Many lab-scale FO studies have been conducted according to the "method of initial rates" in which the rate is measured over a short period of time during which the concentration of the product and reactant are assumed to undergo minimal change. This method is only valid if the mixing of the reactants and reaching steady-state conditions is much faster than the reaction being studied such that steady-state conditions dominate the experiment. Achieving and measuring data over a steady-state regime is a serious concern for many FO systems including the draw solution/membranes combinations considered in this study. The "method of initial rates" is useful when it is not possible to continuously monitor reaction progress or a product impacts the kinetics. It is not entirely clear why the "method of initial rates" has 
become standard practice for FO research given the ease of continually monitoring $J_{w}$ through change in mass and the ability to hold either the feed of draw solution constant through a large solution reservoir compared to the membrane coupon being studied $\left(>200 \mathrm{~L} / \mathrm{m}^{2}\right)$. Using the "method of initial rates" does limit variability that develops reverse solute flux, membrane damage, or error that could propagate from continually recalculating the concentration. In practice a "method of initial rates" is applied to an FO experiment by discarding the first 1-5 min as a pre-steady-state period and then averaging the next $10-20$ min to yield the "rate" for a given set of concentration conditions. In most of these experiments both the feed and the draw solution reservoirs are large compared to the membrane coupon being studied (>200 $\mathrm{L} / \mathrm{m}^{2}$ ) and the system reaches steady-state quickly.

Large reservoirs are not practical for many draw solutes currently being explored including many SPS. Furthermore it appears the SPS draw/membrane system has a prolonged pre-steady-state period prior to reaching the concentration dependent steady-state, Figure 3. The values reported in Figure 4 are based on the initial steady-state of our experiments generally 30 min into a run. Because our reservoirs were small $\left(<200 \mathrm{~L} / \mathrm{m}^{2}\right)$ it was necessary to calculate the draw solution concentration in the middle of this region. In most situations we ran these experiments for several hours the concentration of the draw solution was continual tracked and values recorded and compared independent of the starting point. This provided kinetic data for a range of concentrations during every experimental run and ensured that membrane performed in a stable manner. While these values are not reported they substantiate the low concentration values that are reported. 


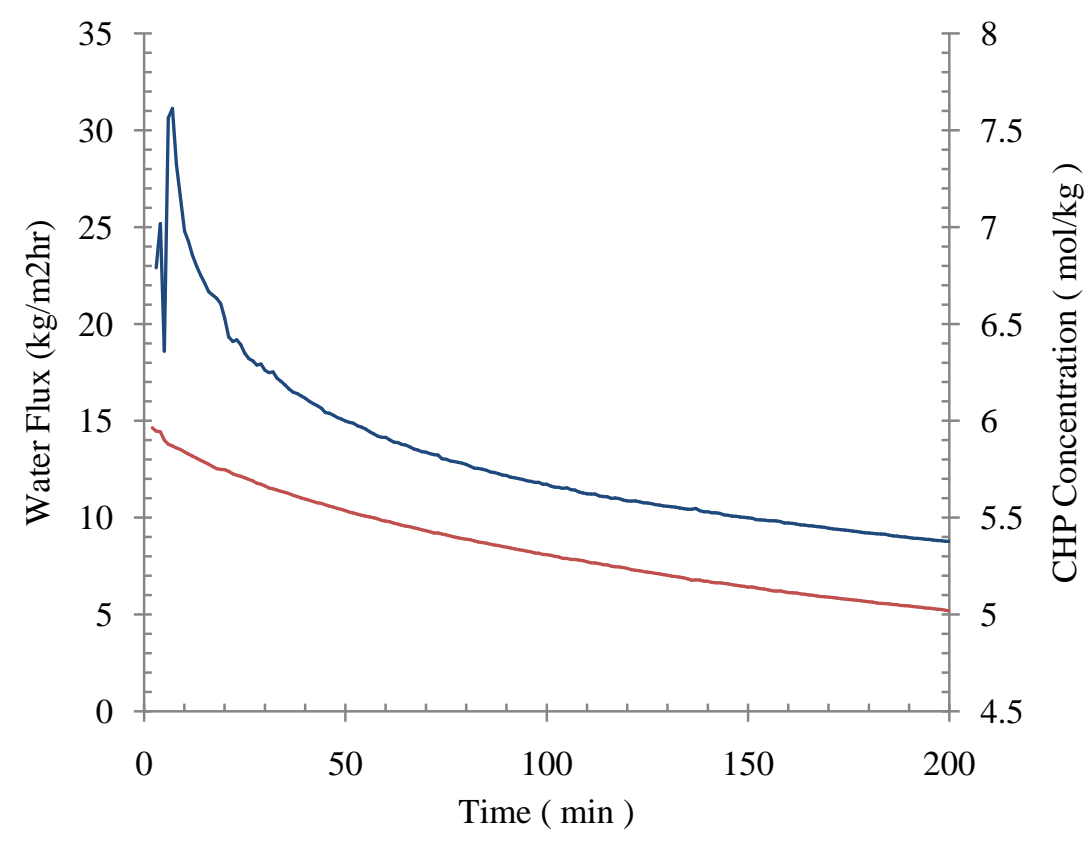

Figure 3. Representative water flux experiment (left axis, blue solid line) and draw solution concentration drop (right axis, red dashed line) when using a CHP draw solution TFC polyamide membrane (FO mode) at $25^{\circ} \mathrm{C}$. The pre-steady-state region (<30 min) and steady-state region (>30 min) are both identified.

The flux performance was studied while varying both the initial CHP draw solute concentrations ( $\sim 1$ to $5 \mathrm{~mol} / \mathrm{Kg}$ by amine) and initial feed solution concentrations ( $0,0.5$, and $1.0 \mathrm{~mol} / \mathrm{Kg} \mathrm{NaCl}$ ). The results of these experiments can be found in Figure 4. At $5.0 \mathrm{~mol} / \mathrm{Kg}$ a CHP solution supplied $\sim 11 \mathrm{Kg} / \mathrm{m}^{2} \mathrm{hr}$ water flux at $25^{\circ} \mathrm{C}$ in FO mode. Higher concentration of CHP draw solutions (5-11.2 mol/Kg) were not studies because the agitation of pumping resulted in draw degassing at our ambient pressure of 0.84 atm (Idaho Falls, ID). It is expected that this degassing can be prevented by providing the draw a modest overpressure (1 to 2 atm) [31]. 


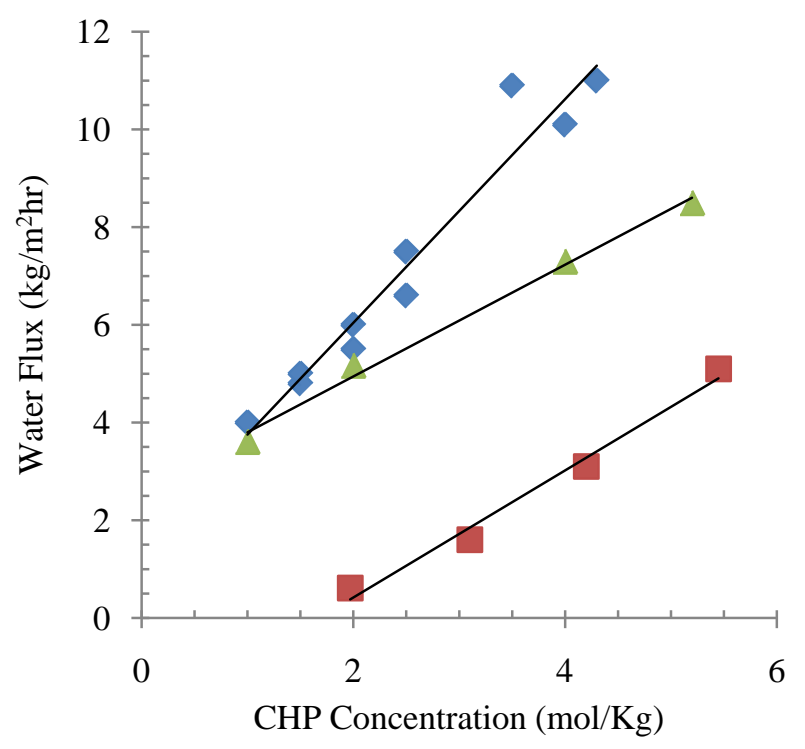

Figure 4. Water flux across a TFC polyamide membrane CHP draw solution at $25{ }^{\circ} \mathrm{C}$ for various draw concentrations (measured by amine) in FO mode for three feed concentrations: blue diamonds DI water, green triangles $0.5 \mathrm{~mol} / \mathrm{Kg} \mathrm{NaCl}$, red squares $1.0 \mathrm{~mol} / \mathrm{Kg} \mathrm{NaCl}$.

The water flux data using a DI water feed solution (Figure 4) has a nearly linear response to the molal concentration which correlates with feed solution osmotic pressure [17,32]. Water flux does not generally correlate linearly with the difference between the feed and draw solution osmotic pressure $[1,25-30]$. There is usually a notable decline in the relative water flux as draw solution concentrations increase. The water flux for the $0.5 \mathrm{~mol} / \mathrm{Kg} \mathrm{NaCl}$ feed solution fits a "decline in response with increasing osmotic pressure difference” model. The observed flux concentration response for the $0.5 \mathrm{~mol} / \mathrm{Kg} \mathrm{NaCl}$ feed solution is smaller than the interpolated initial low concentration response. Interestingly the 1.0 $\mathrm{mol} / \mathrm{Kg} \mathrm{NaCl}$ feed solution data does not appear to follow the non-linearity trend. The concentration range studied is generally linear with zero water flux projected at (1.7 mole/Kg CHP) near the calculated zero osmotic pressure difference concentration of (1.2 mol/Kg CHP). The concentration flux response (slope) of the $1.0 \mathrm{~mol} / \mathrm{Kg} \mathrm{NaCl}$ feed solution at $1.30 \mathrm{Kg}\left(\mathrm{m}^{2} \mathrm{hr}(\mathrm{mol} / \mathrm{kg})\right)^{-1}$ is similar to the $0.5 \mathrm{~mol} / \mathrm{Kg}$ 
$\mathrm{NaCl}$ feed solution response of $1.14 \mathrm{Kg}\left(\mathrm{m}^{2} \mathrm{hr}(\mathrm{mol} / \mathrm{kg})\right)^{-1}$ over the range concentrations measured. With flux data for more membranes it will be interesting to compare this CHP flux data to various theoretical flux models.

These results compare favorably with our previous SPS draw solute data. Based on initial flux values it was found that $7.6 \mathrm{~mol} / \mathrm{Kg}$ DMCHA provided a $J_{w}$ of $\sim 22 \mathrm{Kg} / \mathrm{m}^{2} \mathrm{hr}$ at $30{ }^{\circ} \mathrm{C}$ in PRO mode with a CTA membrane [11]. The difference between PRO and FO are more pronounced when the feed solution has a low concentration, such as $0.5 \mathrm{~mol} / \mathrm{Kg} \mathrm{NaCl}$. A number of physical conditions were changed between these earlier DMCHA studies and the current CHP studies: the membrane (CTA $\rightarrow$ polyamide TFC), membrane orientation (PRO mode $\rightarrow$ FO mode), temperature $\left(30^{\circ} \mathrm{C} \rightarrow 25^{\circ} \mathrm{C}\right.$ ), and kinetic monitoring (method of initial rates $\rightarrow$ continual monitoring). To directly compare the two systems a 5 $\mathrm{mol} / \mathrm{Kg}$ DMCHA draw solution was operated against a $0.5 \mathrm{~mol} / \mathrm{Kg} \mathrm{NaCl}$ feed solution in $\mathrm{FO}$ mode using the TFC membrane to yield a $J_{w}$ of $\sim 11 \mathrm{Kg} / \mathrm{m}^{2} \mathrm{hr}$ at $25^{\circ} \mathrm{C}$. This is very similar to the $\sim 8.5 \mathrm{Kg} / \mathrm{m}^{2} \mathrm{hr}$ water flux produced by $5 \mathrm{~mol} / \mathrm{Kg}$ polar CHP draw solution under the same conditions. The reduced flux of CHP relative to DMCHA was expected based on the relative mass transport properties of CHP and DMCHA [23]. While CHP provides less flux its other advantages in terms of better degassing performance, improved material compatibility, and reduced volatility more than makes up for a modest reduction in flux. The water flux by CHP draw solution is still high relative to many other proposed draw solution systems.

For the reasons outlined above comparing draw solutes is difficult. For example, PRO mode experiments generally provide higher flux than FO mode experiments. The membrane also has a major impact on water flux when used against a pure water feed solution. As a result pure water feed studies poorly demonstrates draw solute performance characteristics. Draw solutes are better tested against a representative feed solution with the most common being $\mathrm{NaCl}$ solution with a concentration around 0.4-0.6 mol/Kg (or molar) whose osmotic pressure is comparable to seawater (osmotic pressures around 1 
Osm or 25 bar). A number of comparable draw solute systems have been reported in the recent literature,

Table 1.

Table 1. Water flux $J_{w}$ performance of various draw solutes.

\begin{tabular}{|c|c|c|c|c|c|}
\hline Draw solution & $\begin{array}{l}\text { Draw solution } \\
\text { concentration }\end{array}$ & $\begin{array}{l}\text { NaCl feed } \\
\text { solution } \\
\text { concentration }\end{array}$ & $\begin{array}{l}\text { Membrane } \\
\text { type and } \\
\text { orientation }\end{array}$ & $\begin{array}{l}\text { Water flux } \\
\mathrm{J}_{\mathrm{w}} \\
\left(\mathrm{Kg} / \mathrm{m}^{2} \mathrm{hr}\right) \\
\end{array}$ & Ref. \\
\hline SPS - CHP & $5 \mathrm{~mol} / \mathrm{Kg}$ & $0.5 \mathrm{~mol} / \mathrm{Kg}$ & $\begin{array}{l}\text { TFC } \\
\text { FO Mode }\end{array}$ & 8.5 & $\begin{array}{l}\text { This } \\
\text { work }\end{array}$ \\
\hline SPS - DMCHA & $5 \mathrm{~mol} / \mathrm{Kg}$ & $0.5 \mathrm{~mol} / \mathrm{Kg}$ & $\begin{array}{l}\text { TFC } \\
\text { FO Mode }\end{array}$ & 11 & $\begin{array}{l}\text { This } \\
\text { work }\end{array}$ \\
\hline ammonia- $\mathrm{CO}_{2}$ & $4.5 \mathrm{M}$ & $0.5 \mathrm{M}$ & $\begin{array}{l}\text { CTA } \\
\text { FO Mode }\end{array}$ & 20.8 & [27] \\
\hline ammonia- $\mathrm{CO}_{2}$ & $6 \mathrm{M}$ & $0.5 \mathrm{M}$ & $\begin{array}{l}\text { CTA } \\
\text { FO Mode }\end{array}$ & 22.4 & [27] \\
\hline $\begin{array}{l}\text { sodium acetate modified } \\
\text { poly(amidoamine) } \\
\text { dendrimers }\end{array}$ & 33 and $40 \mathrm{wt} \%$ & $0.6 \mathrm{M}$ & $\begin{array}{l}\text { TFC } \\
\text { FO Mode }\end{array}$ & $<5$ & {$[33]$} \\
\hline $\begin{array}{l}\text { di(ethylene glycol) } \\
n \text {-hexyl ether }\end{array}$ & $12 \mathrm{~mol} / \mathrm{Kg}$ & $0.6 \mathrm{~mol} / \mathrm{Kg}$ & $\begin{array}{l}\text { CTA } \\
\text { PRO Mode }\end{array}$ & $\sim 0.6$ & [34] \\
\hline $\begin{array}{l}\mathrm{Na}^{+} \text {-functionalized } \\
\text { carbon quantum dots }\end{array}$ & $0.4 \mathrm{~g} / \mathrm{ml}$ & $0.6 \mathrm{M}$ & $\begin{array}{l}\text { TFC } \\
\text { PRO Mode }\end{array}$ & 7.3 & {$[35]$} \\
\hline sodium lignin sulfonate & $\begin{array}{l}600 \mathrm{~g} / \mathrm{Kg} \\
(37.5 \mathrm{wt} \%)\end{array}$ & $\begin{array}{l}30,000 \mathrm{ppm} \\
\sim 0.53 \mathrm{~mol} / \mathrm{Kg}\end{array}$ & $\begin{array}{l}\text { CTA } \\
\text { FO Mode }\end{array}$ & $<5$ & [36] \\
\hline $\begin{array}{l}\text { poly[2-(dimethylamino) } \\
\text { ethyl methacrylate] }\end{array}$ & $23-38$ wt $\%$ & $0.4 \mathrm{~mol} / \mathrm{Kg}$ & PRO Mode & $<4$ & [3] \\
\hline
\end{tabular}

Clearly ammonia- $\mathrm{CO}_{2}$ solutions provides the greatest flux of the systems listed in Table 1.

However, the ammonia- $\mathrm{CO}_{2}$ system suffers from issues associated with separation of the draw and product water $\left(\mathrm{CO}_{2}\right.$ degassing) $[18,19]$ and reverse solute flux. As noted DMCHA draw has similar degassing issues. Once membrane orientation and feed solution concentration are considered the water flux produced by a $5 \mathrm{~mol} / \mathrm{Kg} \mathrm{CHP}$ draw solution is competitive against all the remaining draw solutions listed in Table 1. Furthermore, both the cost of CHP and draw solute regeneration process for CHP are expected to be more economic than nearly any other next generation draw solute reported to date. 


\subsection{Long-Term Flux Studies}

In earlier studies a major problem with the combination of DMCHA draw solute and CTA membrane was their mutual incompatibility. Moving to the combination of a CHP draw solute and polyamide TFC has resulted in an FO process with better stability. The same TFC membrane was used for periods of 4 to 8 hrs against 4 different draw solutions which initially started at $3 \mathrm{~mol} / \mathrm{Kg}$ (by amine) and diluted to $2 \mathrm{~mol} / \mathrm{Kg}$ or less during the experiment with no cleaning or special treatment between runs. The total run time was 32 hrs. The flux during the initial 4 hours of each run were consistent with the first and last run with a flux decline $\left(\sim 6 \mathrm{Kg} / \mathrm{m}^{2} \mathrm{hr} \rightarrow \sim 3.8 \mathrm{Kg} / \mathrm{m}^{2} \mathrm{hr}\right)$ that can be attributed to dilution of the draw solution ( $\sim 3 \mathrm{~mol} / \mathrm{Kg} \rightarrow \sim 2 \mathrm{~mol} / \mathrm{Kg})$, Figure 5 . While this was only a preliminary study of membrane compatibility it is very promising and suggests good durability of the TFC membrane upon exposure to the draw.

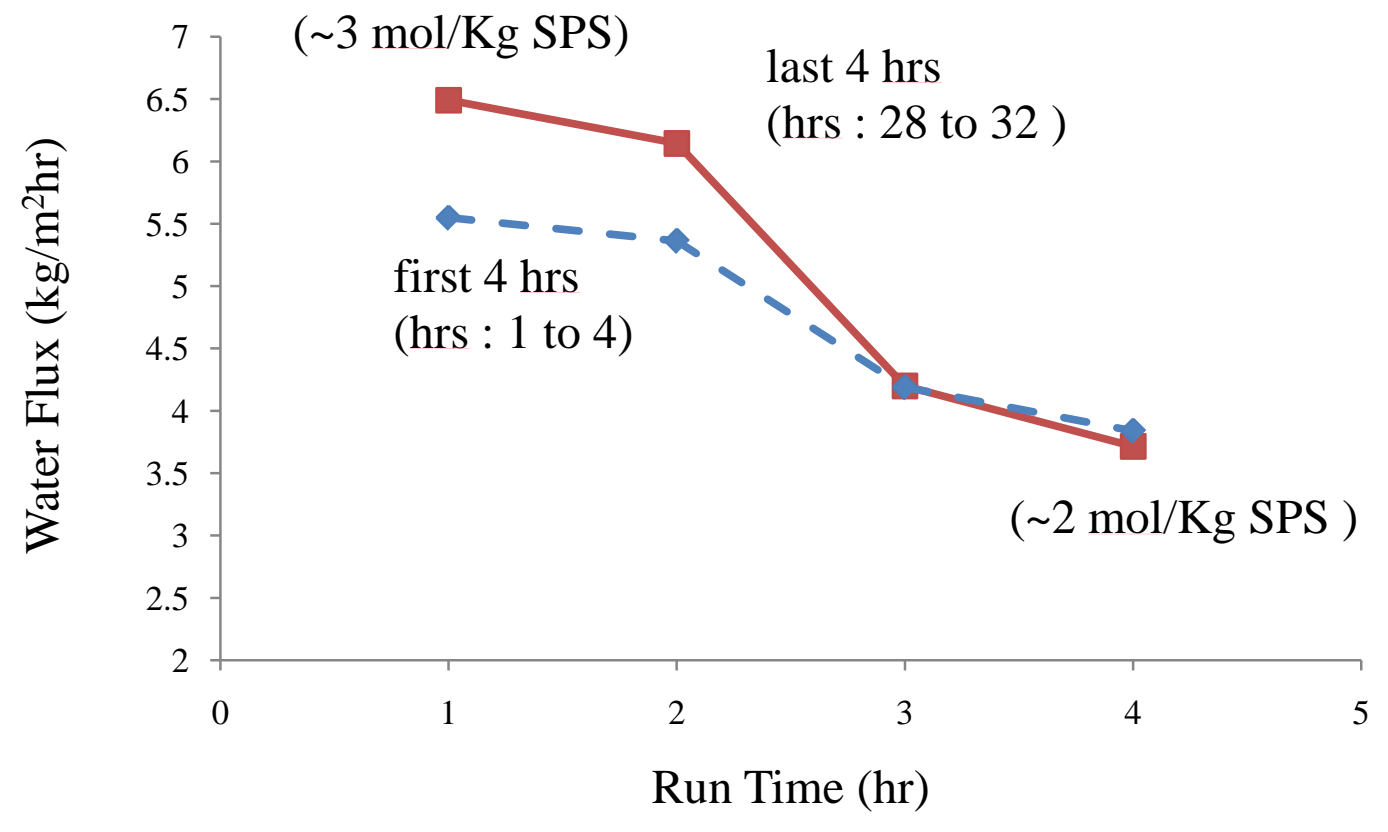

Figure 5. Water flux across a TFC polyamide membrane in FO mode resulting from exposure of multiple CHP draw solutions (initially $\sim 3 \mathrm{~mol} / \mathrm{Kg}$ ) against a DI water feed at 
$25{ }^{\circ} \mathrm{C}$ declining to $\sim 2 \mathrm{~mol} / \mathrm{Kg}$ over a 4 hour period. Blue diamonds hours 1 to 4 and red squares solid line hours 28-32.

\subsection{Reverse Solute Flux}

Reverse solute flux is a well-known challenge for simple inorganic salts and is generally less of a concern for larger molecular draw solutes which usually have very low membrane permeabilities. Small organics, such as SPS, lie somewhere in between inorganic salts and large molecules in terms of molecular size. While small molecules may be large enough to avoid diffusing through a membrane it may have permeation mechanisms unavailable to inorganic solutes. For this reason we actively interrogated the reverse solute flux for CHP draw solutions over a ranger of conditions, Table 2.

Table 2. The $J_{s}$ for all conditions studied.

\begin{tabular}{|c|c|c|c|c|c|}
\hline $\begin{array}{c}\text { NaCl Feed } \\
(\mathrm{mol} / \mathrm{Kg})\end{array}$ & $\begin{array}{l}\text { CHP Draw } \\
(\mathrm{mol} / \mathrm{Kg})\end{array}$ & $\begin{array}{c}\text { Water Flux } \\
J_{w}\left(\mathrm{Kg} / \mathrm{m}^{2} \mathrm{hr}\right)\end{array}$ & $\begin{array}{c}\text { Reverse solute flux } \\
J_{s}\left(\mathrm{Kg} / \mathrm{m}^{2} \mathrm{hr}\right)\end{array}$ & $\begin{array}{c}J_{w} / J_{s} \\
(\mathrm{Kg} / \mathrm{Kg})\end{array}$ & $\begin{array}{c}J_{w} / J_{s} \\
(\mathbf{L} / \mathbf{m o l})\end{array}$ \\
\hline 0.0 & 1 & 4.0 & 0.0074 & 781 & 179 \\
\hline 0.0 & 2 & 6.3 & 0.0045 & 1400 & 321 \\
\hline 0.0 & 4 & 10.6 & 0.0038 & 2752 & 631 \\
\hline 0.5 & 1 & 3.6 & 0.0060 & 602 & 138 \\
\hline 0.5 & 2 & 5.2 & 0.0080 & 646 & 148 \\
\hline 0.5 & 4 & 7.3 & 0.0060 & 1217 & 279 \\
\hline 0.5 & 5 & 8.5 & 0.0040 & 2125 & 487 \\
\hline 1.0 & 2 & 0.6 & 0.0093 & 66 & 15 \\
\hline 1.0 & 3 & 1.6 & 0.0094 & 170 & 39 \\
\hline 1.0 & 4 & 3.1 & 0.0033 & 939 & 215 \\
\hline 1.0 & 5 & 5.1 & 0.0094 & 543 & 124 \\
\hline
\end{tabular}

The reverse solute flux was studied with three feed solutions (DI water, $0.5 \mathrm{~mol} / \mathrm{Kg} \mathrm{NaCl}$, and 1.0 $\mathrm{mol} / \mathrm{Kg} \mathrm{NaCl}$ ) against draw solution concentration that varied from 1 to $5 \mathrm{~mol} / \mathrm{Kg}$ according to the amine concentration, Table 2. While there may be subtle trends in the draw solute reverse solute flux they are 
largely independent of the feed and draw solution concentrations. As a result the ratio of the water flux to reverse solute flux, $J_{w} / J_{s}$, primarily depends on the water flux.

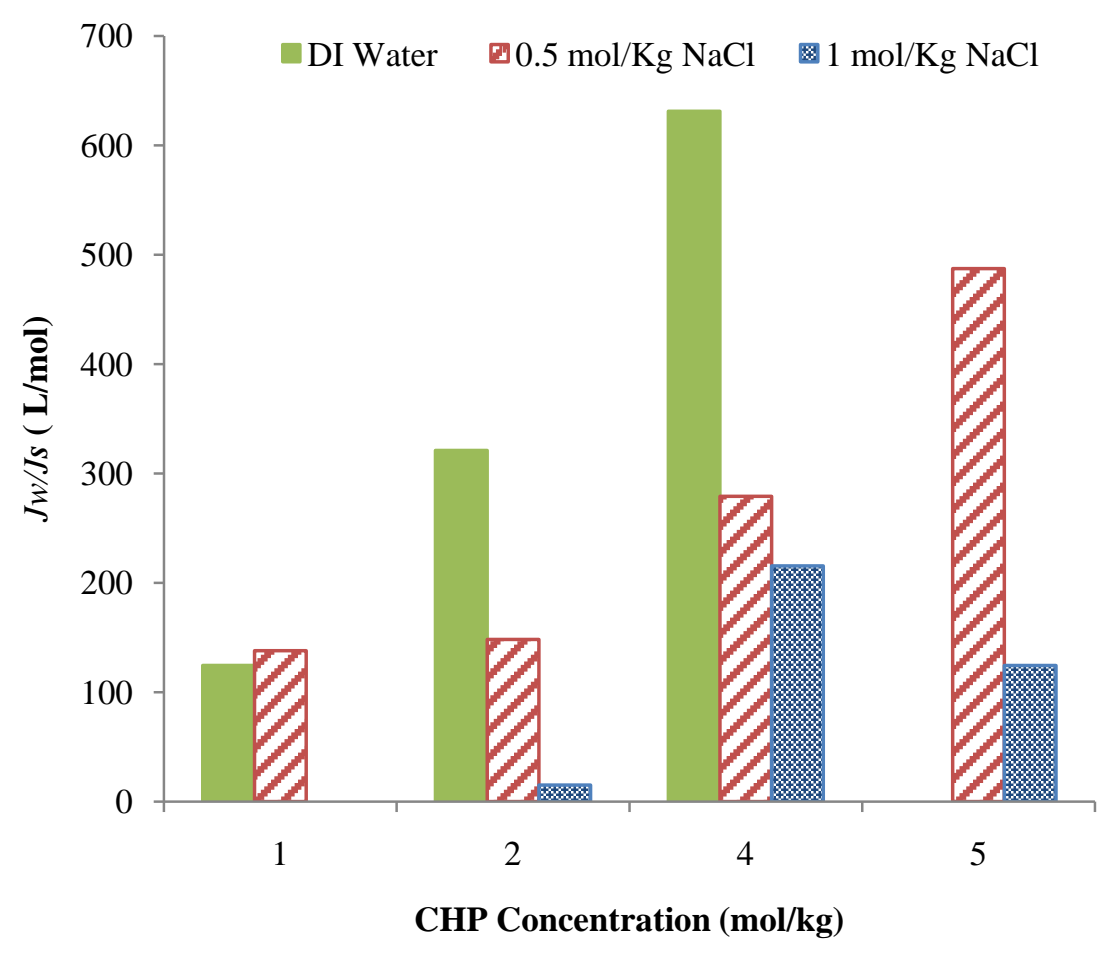

Figure 6. Ratio of $J_{w} / J_{s}(\mathrm{~L} / \mathrm{mol})$ for CHP draw solutions at $25^{\circ} \mathrm{C}$.

The condition independence of $J_{s}$ may be a result of a number of different phenomena. One possibility is that only cyclohexylpiperidine (versus cyclohexylpiperidinium) was the primary species that diffused through the membrane. The concentration of cyclohexylpiperidine is a minor constituent that under the simplest equilibrium and solubility models is expected to be have a fixed value regardless of the cyclohexylpiperidinium concentration. A second explanation is that the dominant transport mechanism differs between water (pore diffusivity) and CHP (membrane solubility). 
Regardless of the origin of the difference, the result was that better selectivity is observed at high draw concentration with higher water flux, Figure 6. These selectivities are similar to those observed in related systems [6]. Although good, more work is needed to increase selectivity. Since $J_{s}$ is independent of $J_{w}$ it is expected that a membrane can be tailored to significantly reduce $J_{s}$ without impacting $J_{w}$.

\subsection{Draw Solution Degassing}

The SPS presented here are amine- $\mathrm{CO}_{2}$ salts which are a sub-category of thermolytic solutes. SPS are distinct from other amine- $\mathrm{CO}_{2}$ salts in that the amine is an organic liquid in its aprotic form rather than a gas, solute, gel, or solid. The transformation which makes SPS an attractive draw solute is the ability to drastically change its aqueous concentration by modest manipulations in temperature and $\mathrm{CO}_{2}$ pressure. Taking full advantage of this transformation both, forward and reverse, is a key challenge in developing SPS as a draw solute.

Upon addition of ambient pressure of $\mathrm{CO}_{2}$ the water immiscible nonpolar $\mathrm{CHP}$ readily produces the corresponding polar aqueous ammonium bicarbonate acid-base salt. To research a saturated equilibrium ammonium bicarbonate requires prolonged exposure to $\mathrm{CO}_{2}$; the rate of conversion slows as the equilibrium state is approached. This limitation does not hamper a SPS-FO process. A full concentration equilibrium state is not necessary for an ODMP; as previously mentioned increasing concentrations have diminishing returns in terms of flux. It is also possible to speed the process with the addition of modest pressure. Increased concentrations also have the drawbacks of increased viscosity and

reduced diffusion. A draw solution that can be produced in a kinetically reasonable amount of time using equipment with reasonable capital cost is generally preferred to a draw with a higher osmotic pressure but worse formation kinetics and cost.

At whatever concentration is selected, the degassing transition from the polar acid-base salt to nonpolar tertiary-amine must be rapid and achieve near completeness. This conversion is also where the thermodynamic cost of desalination is paid in an ODMP when a thermolytic draw solute is employed. 
Any residual draw solute must be removed using filtration (like RO or UF/NF separation of dissolved solids), which presumably is intended to be replaced by the thermolytic process. Previous models of thermolytic draw solute removal[37] may have been overly optimistic in light of more recent experimental results $[18,19]$. The concentration dependence of the $\mathrm{CO}_{2}$ removal from amines is better highlighted in the carbon capture literature [38-43]. In the case of DMCHA at full concentration it started degassing as early as $25{ }^{\circ} \mathrm{C}$, requiring viscosity measurements to be made at $15{ }^{\circ} \mathrm{C}$, however as will shortly be illustrated DMCHA requires nearly reflux conditions to fully remove the $\mathrm{CO}_{2}$ content.

To test the degassing process tertiary-ammonium bicarbonate, solutions were recirculated through a high surface area heat exchanger with a gear pump. The heat exchanger outer jacket was attached to a recirculating heat bath that could be set to the desired temperature. As ammonium bicarbonate solutions were pumped through the heat exchanger, gas was evolved, and organic layer formed. The reaction progress was monitored with a freezing point osmometry measurement on the aqueous layer. The degassing process, in the proposed system, is intended to minimize the SPS concentration in the product water that must be removed through an osmotic filtration or another mechanism to capture residual amine/ammonium. Because of the presence of the SPS, and the fact that osmotic pressure that can influence the cost of additional processing methods, osmometry serves as an ideal method to measure reaction progress. However, this method has limitations as it is not designed to yield detailed kinetic numbers that elucidate key reaction rates, $\mathrm{CO}_{2}$ pressure effects, surface area effects, and material interaction information that would allow the results to be directly extrapolated to an industrial process. The intent of these experiments was a temperature sensitivity comparison between the amines to highlight relative advantage of CHP over DMCHA and guide future work in optimizing the degasser design and kinetic studies.

When polar DMCHA solution starting from $\sim 1.5 \mathrm{~mol} / \mathrm{kg}$ by amine was degassed at $70{ }^{\circ} \mathrm{C}$ in our experimental apparatus it would reach 2.4 Osm/Kg after 6 hrs, Figure 7, more than twice the osmotic pressure of sea water. For DMCHA to reach a reasonable degassing rate the temperature had to be raised 
significantly. At $95{ }^{\circ} \mathrm{C}$ polar DMCHA resulted in solution of $0.35 \mathrm{Osm} / \mathrm{Kg}$ concentration within $3 \mathrm{hrs}$. The less polar higher molecular weight CHP ammonium bicarbonate solution when degassed at $70{ }^{\circ} \mathrm{C}$ reached $0.6 \mathrm{Osm} / \mathrm{Kg}$ within $3 \mathrm{hrs}$ and dropped to $0.2 \mathrm{Osm} / \mathrm{Kg}$ after extended treatment, Figure 7. Increasing the temperature to $80{ }^{\circ} \mathrm{C}$ resulted in even faster degassing reaching $0.2 \mathrm{Osm} / \mathrm{Kg}$ within $3 \mathrm{hrs}$ and dropped to $<0.1 \mathrm{Osm} / \mathrm{Kg}$ after extended treatment. The performance of degassing $\mathrm{CHP}$ at $80{ }^{\circ} \mathrm{C}$ was very similar to the performance of degassing DMCHA at $95^{\circ} \mathrm{C}$, Figure 7 . The experiment apparatus may be incapable of differentiating the performance of the two amines at these rates and the observed performance was based on the limits of the apparatus or the removal of $\mathrm{CO}_{2}$ from the solution. Regardless these experiments demonstrated that the CHP is effectively degassed at a much lower temperatures than DMCHA. Further studies relative to the effects of nucleation material, surface area, temperature and pressure are required [42]. This data will allow the design of an optimized industrial system for the SPS degassing process. 


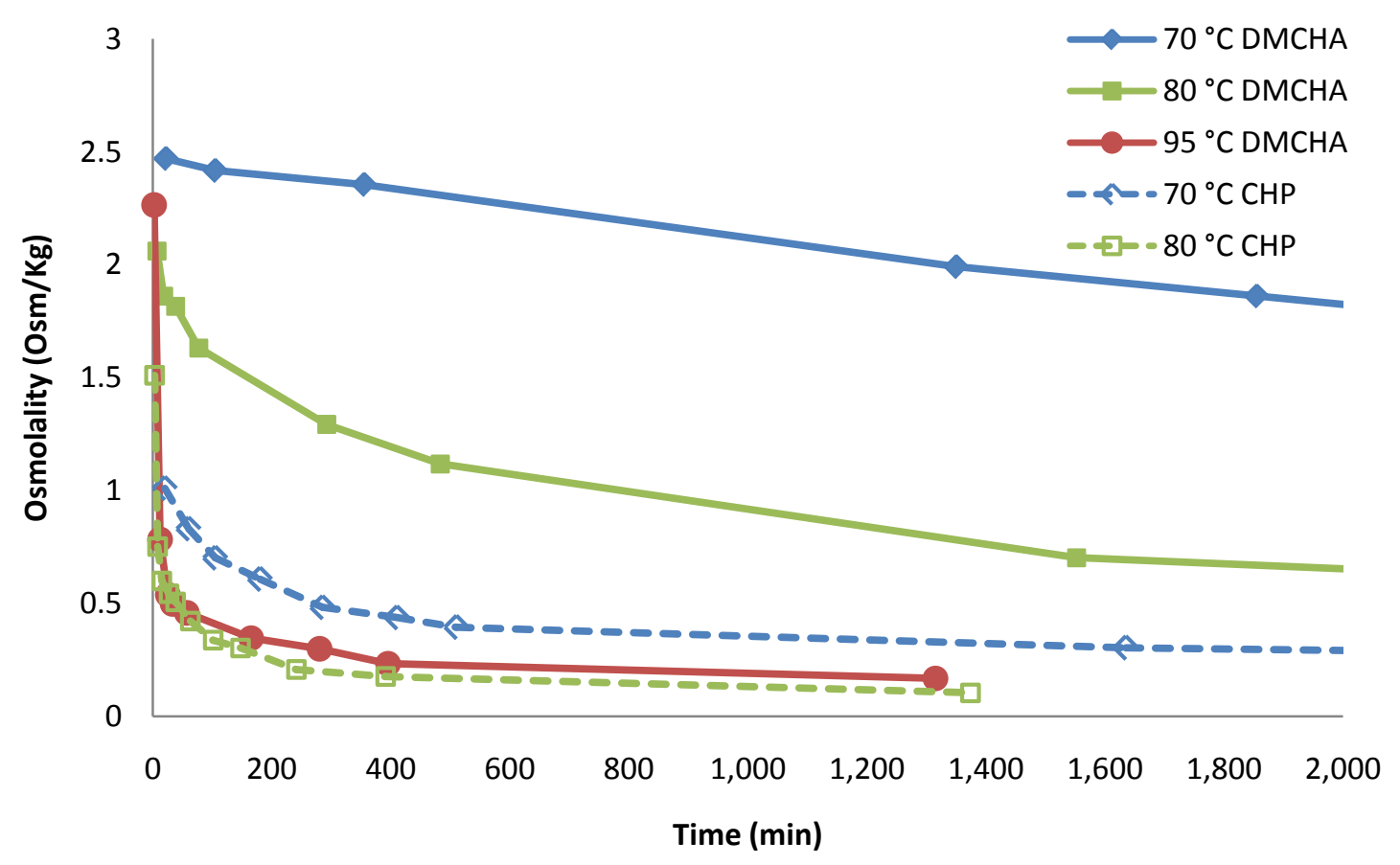

Figure 7. 1-cyclohexylpiperidinium bicarbonate polar to non-polar transition driven by a circulation through a high surface area heat exchanger at $70{ }^{\circ} \mathrm{C}$.

\section{CONCLUSION}

1-Cyclohexylpiperidine (CHP) displays osmotic pressures (>500 atm) and flux performance comparable to the previously reported $N, N$-dimethylcyclohexylamine with greatly improved material compatibility and degassing performance. The combination of CHP draw solution and polyamide TFC membrane displayed long term stability. Reverse draw solute flux was found to be independent of draw solute concentration while water flux varied proportionally with draw solute concentration suggesting that $J_{S}$ could be minimized without impacting $J_{w}$. The initial degassing studies suggest that $70{ }^{\circ} \mathrm{C}$ should be sufficient to degas CHP at ambient pressure with the use of lower temperatures possible given reduced pressures. These results are very promising and address all of the major challenges in developing an integrated SPS-FO process as identified in our initial SPS-FO study [11]. A forthcoming 
techno-economic process model of SPS-FO is also favorable [44]. The aggregate of this work suggests further research into developing a SPS-FO process is warranted.

\section{ACKNOWLEDGMENTS}

This work was supported by the United States Department of Energy through contract DE-AC07-

05ID14517. Funding was supplied by Idaho National Laboratory via the Laboratory Directed Research and Development Fund (LDRD). The authors also acknowledge Porifera for providing the membranes for this research.

\section{NOMENCLATURE}

$\begin{array}{ll}A_{m} & \text { membrane area } \\ \mathrm{C} & \text { solution concentration } \\ \text { CHP } & \text { 1-cyclohexylpiperidine } \\ \text { CTA } & \text { cellulose triacetate } \\ \text { DMCHA } & N, N \text {-dimethylcyclohexylamine } \\ \text { FO } & \text { forward osmosis } \\ \text { FO Mode } & \text { active layer towards feed solution } \\ J_{s} & \text { reverse solute flux } \\ J_{w} & \text { water flux } \\ \text { M } & \text { Solution mass } \\ \text { N(Me) }{ }_{2} \text { Cy } & N, N \text {-dimethylcyclohexylamine } \\ \text { ODMP } & \text { osmotically driven membrane process } \\ \text { PRO Mode } & \text { active layer towards draw solution } \\ \text { QSAR } & \text { quantitative structure activity relationship } \\ \text { RO } & \text { reverse osmosis } \\ \text { TFC } & \text { thin film composite } \\ \text { SPS } & \text { switchable polarity solvent } \\ \text { V } & \text { colution volume } \\ & \\ \text { Subscript } & \\ \text { F } & \text { feed solution } \\ \text { D } & \text { draw solution }\end{array}$




\section{REFERNCES}

[1] J.R. McCutcheon, R.L. McGinnis, M. Elimelech, A novel ammonia--carbon dioxide forward (direct) osmosis desalination process, Desalination. 174 (2005) 1-11. doi:10.1016/j.desal.2004.11.002.

[2] D.L. Shaffer, J.R. Werber, H. Jaramillo, S. Lin, M. Elimelech, Forward osmosis: Where are we now?, Desalination. 356 (2015) 271-284. doi:10.1016/j.desal.2014.10.031.

[3] Y. Cai, W. Shen, R. Wang, W.B. Krantz, A.G. Fane, X. Hu, CO2 switchable dual responsive polymers as draw solutes for forward osmosis desalination, Chem. Commun. 49 (2013) 8377-8379. doi:10.1039/C3CC43289K.

[4] Q. Zhao, N. Chen, D. Zhao, X. Lu, Thermoresponsive Magnetic Nanoparticles for Seawater Desalination, ACS Appl. Mater. Interfaces. 5 (2013) 11453-11461. doi:10.1021/am403719s.

[5] J. Kim, J.-S. Chung, H. Kang, Y. Yu, W. Choi, H. Kim, et al., Thermo-responsive copolymers with ionic group as novel draw solutes for forward osmosis processes, Macromol. Res. 22 (2014) 963970. doi:10.1007/s13233-014-2142-6.

[6] C. Boo, Y.F. Khalil, M. Elimelech, Performance evaluation of trimethylamine-carbon dioxide thermolytic draw solution for engineered osmosis, J. Membr. Sci. 473 (2015) 302-309. doi:10.1016/j.memsci.2014.09.026.

[7] Y. Hartanto, S. Yun, B. Jin, S. Dai, Functionalized thermo-responsive microgels for high performance forward osmosis desalination, Water Res. 70 (2015) 385-393. doi:10.1016/j.watres.2014.12.023.

[8] A. Zhou, H. Luo, Q. Wang, L. Chen, T.C. Zhang, T. Tao, Magnetic thermoresponsive ionic nanogels as novel draw agents in forward osmosis, RSC Adv. 5 (2015) 15359-15365. doi:10.1039/C4RA12102C.

[9] R. Ou, Y. Wang, H. Wang, T. Xu, Thermo-sensitive polyelectrolytes as draw solutions in forward osmosis process, Desalination. 318 (2013) 48-55. doi:10.1016/j.desal.2013.03.022.

[10] P.G. Jessop, L. Kozycz, Z.G. Rahami, D. Schoenmakers, A.R. Boyd, D. Wechsler, et al., Tertiary amine solvents having switchable hydrophilicity, Green Chem. 13 (2011) 619-623. doi:10.1039/C0GC00806K.

[11] M.L. Stone, C. Rae, F.F. Stewart, A.D. Wilson, Switchable polarity solvents as draw solutes for forward osmosis, Desalination. 312 (2013) 124-129. doi:10.1016/j.desal.2012.07.034.

[12] A. Achilli, T.Y. Cath, E.A. Marchand, A.E. Childress, The forward osmosis membrane bioreactor: A low fouling alternative to MBR processes, Desalination. 239 (2009) 10-21. doi:10.1016/j.desal.2008.02.022.

[13] S. Lee, C. Boo, M. Elimelech, S. Hong, Comparison of fouling behavior in forward osmosis (FO) and reverse osmosis (RO), J. Membr. Sci. 365 (2010) 34-39. doi:10.1016/j.memsci.2010.08.036.

[14] B. Mi, M. Elimelech, Organic fouling of forward osmosis membranes: Fouling reversibility and cleaning without chemical reagents, J. Membr. Sci. 348 (2010) 337-345. doi:10.1016/j.memsci.2009.11.021.

[15] Z.-Y. Li, V. Yangali-Quintanilla, R. Valladares-Linares, Q. Li, T. Zhan, G. Amy, Flux patterns and membrane fouling propensity during desalination of seawater by forward osmosis, Water Res. 46 (2012) 195-204. doi:10.1016/j.watres.2011.10.051.

[16] Q. She, X. Jin, Q. Li, C.Y. Tang, Relating reverse and forward solute diffusion to membrane fouling in osmotically driven membrane processes, Water Res. 46 (2012) 2478-2486. doi:10.1016/j.watres.2012.02.024.

[17] A.D. Wilson, F.F. Stewart, Deriving osmotic pressures of draw solutes used in osmotically driven membrane processes, J. Membr. Sci. 431 (2013) 205-211. doi:10.1016/j.memsci.2012.12.042.

[18] N. Hancock, Engineered Osmosis for Energy Efficient Separations: Optimizing Waste Heat Utilization FINAL SCIENTIFIC REPORT DOE F 241.3 DE-EE0003467, 2013. http://www.osti.gov/bridge/servlets/purl/1067379/. 
[19] R.L. McGinnis, N.T. Hancock, M.S. Nowosielski-Slepowron, G.D. McGurgan, Pilot demonstration of the NH3/CO2 forward osmosis desalination process on high salinity brines, Desalination. 312 (2013) 67-74. doi:10.1016/j.desal.2012.11.032.

[20] A.D. Wilson, F.F. Stewart, Structure-function study of tertiary amines as switchable polarity solvents, RSC Adv. 4 (2014) 11039-11049. doi:10.1039/C3RA47724J.

[21] J.S. McNally, A.D. Wilson, Density Functional Theory Analysis of the Impact of Steric Interaction on the Function of Switchable Polarity Solvents, J. Phys. Chem. B. (2015) (accepted).

[22] Calculated using Advanced Chemistry Development (ACD/Labs) Software V11.02 (C) 1994-2014 ACD/Labs), n.d. https://scifinder.cas.org/scifinder/view/scifinder/scifinderExplore.jsf (accessed April 11, 2014).

[23] A.D. Wilson, C.J. Orme, Concentration dependent speciation and mass transport properties of switchable polarity solvents, RSC Adv. 5 (2015) 7740-7751. doi:10.1039/C4RA08558B.

[24] C. Samorì, L. Pezzolesi, D.L. Barreiro, P. Galletti, A. Pasteris, E. Tagliavini, Synthesis of new polyethoxylated tertiary amines and their use as Switchable Hydrophilicity Solvents, RSC Adv. 4 (2014) 5999-6008. doi:10.1039/C3RA47144F.

[25] G.T. Gray, J.R. McCutcheon, M. Elimelech, Internal concentration polarization in forward osmosis: role of membrane orientation, Desalination. 197 (2006) 1-8. doi:10.1016/j.desal.2006.02.003.

[26] J.R. McCutcheon, M. Elimelech, Influence of concentrative and dilutive internal concentration polarization on flux behavior in forward osmosis, J. Membr. Sci. 284 (2006) 237-247. doi:10.1016/j.memsci.2006.07.049.

[27] J.R. McCutcheon, R.L. McGinnis, M. Elimelech, Desalination by ammonia-carbon dioxide forward osmosis: Influence of draw and feed solution concentrations on process performance, J. Membr. Sci. 278 (2006) 114-123.

[28] C.H. Tan, H.Y. Ng, Modified models to predict flux behavior in forward osmosis in consideration of external and internal concentration polarizations, J. Membr. Sci. 324 (2008) 209-219. doi:10.1016/j.memsci.2008.07.020.

[29] C.H. Tan, H.Y. Ng, Revised external and internal concentration polarization models to improve flux prediction in forward osmosis process, Desalination. 309 (2013) 125-140. doi:10.1016/j.desal.2012.09.022.

[30] K. Lutchmiah, L. Lauber, K. Roest, D.J.H. Harmsen, J.W. Post, L.C. Rietveld, et al., Zwitterions as alternative draw solutions in forward osmosis for application in wastewater reclamation, J. Membr. Sci. 460 (2014) 82-90. doi:10.1016/j.memsci.2014.02.032.

[31] J. Durelle, J.R. Vanderveen, Y. Quan, C. Chalifoux, J. Kostin, P.G. Jessop, Extending the range of switchable-hydrophilicity solvents, Phys Chem Chem Phys. (2015). doi:10.1039/C4CP05313C.

[32] K.K. Reimund, J.R. McCutcheon, A.D. Wilson, Thermodynamic analysis of energy density in pressure retarded osmosis: The impact of solution volumes and costs, J. Membr. Sci. 487 (2015) 240-248. doi:10.1016/j.memsci.2015.03.076.

[33] D. Zhao, S. Chen, P. Wang, Q. Zhao, X. Lu, A Dendrimer-Based Forward Osmosis Draw Solute for Seawater Desalination, Ind. Eng. Chem. Res. 53 (2014) 16170-16175. doi:10.1021/ie5031997.

[34] D. Nakayama, Y. Mok, M. Noh, J. Park, S. Kang, Y. Lee, Lower critical solution temperature (LCST) phase separation of glycol ethers for forward osmotic control, Phys. Chem. Chem. Phys. 16 (2014) 5319-5325. doi:10.1039/C3CP55467H.

[35] C.X. Guo, D. Zhao, Q. Zhao, P. Wang, X. Lu, Na+-functionalized carbon quantum dots: a new draw solute in forward osmosis for seawater desalination, Chem. Commun. 50 (2014) 7318-7321. doi:10.1039/C4CC01603C.

[36] J. Duan, E. Litwiller, S.-H. Choi, I. Pinnau, Evaluation of sodium lignin sulfonate as draw solute in forward osmosis for desert restoration, J. Membr. Sci. 453 (2014) 463-470. doi:10.1016/j.memsci.2013.11.029.

[37] R.L. McGinnis, M. Elimelech, Energy requirements of ammonia-carbon dioxide forward osmosis desalination, Desalination. 207 (2007) 370-382. 
[38] J. Zhang, J. Chen, R. Misch, D.W. Agar, Carbon dioxide absorption in biphasic amine solvents with enhanced low temperature solvent regeneration, Chem. Eng. Trans. 21 (2010) 169-174.

[39] J. Zhang, R. Misch, Y. Tan, D.W. Agar, Novel Thermomorphic Biphasic Amine Solvents for CO2 Absorption and Low-Temperature Extractive Regeneration, Chem. Eng. Technol. 34 (2011) 14811489. doi:10.1002/ceat.201100099.

[40] J. Zhang, D.W. Agar, X. Zhang, F. Geuzebroek, CO2 absorption in biphasic solvents with enhanced low temperature solvent regeneration, Energy Procedia. 4 (2011) 67-74. doi:10.1016/j.egypro.2011.01.024.

[41] J. Zhang, Y. Qiao, D.W. Agar, Improvement of Lipophilic-Amine-based Thermomorphic Biphasic Solvent for Energy-Efficient Carbon Capture, Energy Procedia. 23 (2012) 92-101. doi:10.1016/j.egypro.2012.06.072.

[42] J. Zhang, Y. Qiao, D.W. Agar, Intensification of low temperature thermomorphic biphasic amine solvent regeneration for CO2 capture, Chem. Eng. Res. Des. 90 (2012) 743-749. doi:10.1016/j.cherd.2012.03.016.

[43] Yudy Halim Tan, Study of CO2-absorption into thermomorphic lipophilic amine solvents, Technischen Universität Dortmund, 2010. https://eldorado.tu-dortmund.de/handle/2003/27427 (accessed February 26, 2014).

[44] D.S. Wendt, C.J. Orme, G.L. Mines, A.D. Wilson, Process Energy Requirements of Switchable Polarity Solvent Forward Osmosis, Desalination. (2015) (submitted simultaneously). 